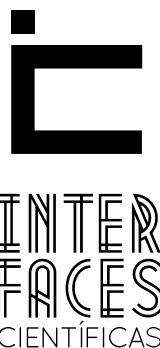

EDUCAÇÃO

\title{
DA CARTA AO AVA: AS TECNOLOGIAS NA CONSTRUÇ̄̃O DE UMA IDENTIDADE NA EAD
}

Lucas C. do Vale ${ }^{1}$

\section{RESUMO}

0 presente artigo tem como finalidade apresentar a evolução da EAD por meio das tecnologias e como elas contribuirão para evolução desta modalidade de ensino. Em paralelo a este relato, será construída uma análise das técnicas mediadoras utilizadas pelos professores em cada uma das tecnologias apresentadas. Assim, o artigo propõe apresentar a contribuição de cada tecnologia para construção da identidade da EAD.

\section{PALAVRAS-CHAVE}

Tecnologias. EAD. Mediação. Identidade.
Simone de Lucena Ferreira²

\section{ABSTRACT}

This article aims to present the development of distance education through technology, and how it contributes to the evolution of this mode of teaching. At the same time, an analysis of the techniques used by teachers in each of the technologies presented will be shown. Thus, the article aims to present the contribution of each technological device to build the identity of the EAD.

\section{KEYWORDS:}

Technologies. E-learning. Mediation. Identity 


\section{RESUMEN}

Este artículo tiene como objetivo presentar el desarrollo de la educación a distancia a través de la tecnología y la forma en que contribuyen al desarrollo de esta modalidad de enseñanza. En paralelo a esta cuenta, se construirá un análisis técnico de los mediadores utilizados por los docentes en cada una de las tecnologías presentadas. De este modo, el artículo tiene como objetivo presentar la contribución de cada tecnología para construir la identidad de la EAD.

\section{PALABRAS CLAVE}

Tecnologías. Educación a Distancia. Mediación. Identidad

\section{INTRODUÇ̄̃O}

Quando se pensa em Educação a Distância, logo remetemos o pensamento para as tecnologias, o que não poderia ser diferente, tratando-se de uma modalidade educacional na qual o uso da tecnologia é indispensável. Mas, afinal, que tecnologia é está? Estaríamos falando das TICs, da WEB 2.0, da tele presença, das WICs e da geolocalização? Poderíamos sim, se tratarmos da EAD em 2012. Entretanto, se estivéssemos em 2030, as tecnologias seriam estas? Fazer este questionamento se faz necessário para que possamos entender como foi, como é e como ser, a escolha das tecnologias contemporânea para uso na EAD.

Nesta perspectiva, ser contemporâneo é ser atual; porém, como definir que a carta, o rádio e os computadores sem acesso internet são contemporâneos? Isso se torna possível quando analisados em seu recorte de tempo. Desta forma, toda tecnologia é contemporânea desde que seja utilizada no seu contexto histórico.
As tecnologias criaram na Educação a Distância marcos que Moore (2007) define como geração e Palhares (2009) define como onda. Neste artigo, faremos uso da definição de Palhares (2009), classificando cada tecnologia como uma onda, fazendo uso da própria justificativa do autor, afirmando que:

[...] as fases da EAD não têm um caráter estanque. Ainda hoje se utilizam formatos de EAD pertencentes a todas as ondas. Assim como o mar, onde não fica muito clara a separação entre as ondas, também na $E A D$, a onda seguinte não tem início no final da anterior, confundindo-se uma com a outra (PALHARES, 2009, p. 48).

Assim, teremos na primeira onda o estudo por correspondência, depois o rádio, o computador não conectado à rede e, por fim, a onda e-learning.

\section{ONDA ESTUDO POR CORRESPONDÊNCIA}

0 recurso impresso foi a primeira tecnologia de comunicação utilizada na Educação a Distância. Com este recurso, se tornou possível a educação por cor- respondência. Nesta metodologia, a mediação professor/aluno acontecia por meio de correspondências nas quais o professor enviava material impresso ou 
manuscrito para o aluno, que depois retornava para o professor com as respostas para as questões ali colocadas. MOORE (2007, p. 25) define este modelo de EAD como "estudo por correspondência" ou "estudo independente".

Segundo estudos do Instituto de Pesquisa Econômica Aplicada (IPEA), é comprovado que, um pouco antes de 1900, já existiam anúncios de cursos profissionalizantes por correspondência em jornais do Rio de Janeiro. Este estudo é apresentado por Alves (2009, p. 09) “[...] pouco antes de 1900, já existiam anúncios em jornal de circulação no Rio de Janeiro oferecendo cursos profissionalizantes por correspondência”.

Não oponente a esta ação isolada, que foi importante para de consolidação da república, cujo marco de referência eram as instalações das escolas internacionais, em 1904, o modelo de ensino estava fundamentado principalmente nos modelos norte americano como afirma Carvalho (2003, p. 32):

\begin{abstract}
A importância dos modelos norte americanos, com que o darwnista Caetano de Campos anelava implantar não só uma nova escola, mas uma nova sociedade é homologada ao movimento de transplantar para o país novas populações, construído elas o tão almejado e luminoso progresso.
\end{abstract}

Os cursos ofertados por correspondência nesta época eram voltados para pessoas que estavam procurando emprego, especialmente nos setores de comércio e serviço.

O processo desta onda sofreu modificação. Assim, sai o professor particular e surgem os institutos ou escolas ofertando cursos. Entretanto, o ensino continuava ocorrendo por correspondência, com envio de materiais didáticos pelos correios, justificando a denominação pelo processo de mediação professor/aluno que ocorria por meio de cartas. Lições, exercícios e até mesmo provas eram enviados da escola para o aluno, ou vice-versa. Todo o processo ocorria por meio do serviço dos Correios; até mesmo os pagamentos.
O estudo por correspondência começava com a matrícula do aluno, que chegava por carta, e a secretaria abria uma pasta para o estudante. Logo depois, o aluno recebia um informativo com o seu número de matrícula e as datas de cumprimento das atividades, das provas e vencimento das mensalidades. Com início dos estudos, os alunos poderiam enviar suas dúvidas e questionamentos por cartas, que seriam respondidas por um grupo de instrutores, que, além de responderem às dúvidas, também elaboravam questões de avaliação. Estes instrutores eram contratados conforme sua atuação profissional com regime de trabalho por meio de plantões semanais.

As provas eram compostas por questões objetivas e subjetivas. As questões subjetivas poderiam ser dissertativas ou avaliativas, como desenhos técnicos. Esta parte era corrigida pelo instrutor; já as objetivas, compostas por questões de múltipla escolha, eram corrigidas por funcionários da secretaria da escola com o auxílio do gabarito. A nota era lançada na ficha do aluno. Outro critério avaliativo era a quantidade de dúvidas e materiais enviados para a pasta do aluno. Está avaliação era feita pela observação desta pasta e quanto maior a quantidade de documentos e mais desgastado o material, mais atividades o aluno teria realizado.

Em cursos técnicos que necessitavam de peças e ferramentas, a escola enviava estes recursos para o estudante, porém isso só ocorria quando eram alcançadas as etapas mais avançadas, como condições de manuseá-las com segurança. Outro critério era conforme o pagamento, ou seja, só eram enviadas quando o aluno contabilizava um número de mensalidades pagas que suprissem os custos. Os pagamentos destes cursos ocorriam por meio da Empresa de Correios e Telégrafos - ECT que oferece, até hoje, a opção de envio de valores, o vale postal. Desta forma, o aluno comprava o vale postal no valor da mensalidade e enviava para a escola. Os funcionários da tesouraria da escola recebiam o dinheiro nos caixas da ECT. 
Todo processo começava e terminava nos correios. O setor do instituto que dava início era o de tiragem, que se responsabilizava em retirar dos correios malas postais de correspondências. Este processo poderia ocorrer mais de uma vez no mesmo dia e, nos anos auges desta onda, uma escola chegava a ter mais de dez mil alunos matriculados por mês, como afirma Rodrigues (2012):

[...] havia 10 mil matrículas por mês em cursos livres. As reservas de vagas neste instituto especializado em EAD (Educação a Distância) eram feitas via cupons de revistas, e o número de cartas era um termômetro do sucesso (RODRIGUES, 2012, p. 38).

Para fazer uso deste meio, o instituto ou escola deveria desenvolver uma organização impecável, pois o recebimento, a circulação e a devolução não poderiam ter falhas. Além da organização, outro processo que se destacava nesta onda foi a elaboração de material didático impresso. Estes institutos desenvolveram um processo que era dividido em seis etapas: autoria, avaliação do editor, mediação pedagógica, avaliação do editor, ilustração e diagramação.

Todas as etapas tinham sua importância. Entretanto, iremos detalhar a mediação pedagógica que tinha como finalidade de se interpor entre aluno e o conhecimento. Desta forma, o material didático impresso tinha função de ligar o aluno ao professor, ou seja, caberia ao material didático fazer a mediação do processo ensino/aprendizagem. A mediação pedagógica ocorria entre a etapa inicial da produção e a revisão final, tendo como base o tema de estudo, a autoaprendizagem e a forma de estudo.

A autoaprendizagem era a fundamental nesta onda. E para garantir isso o material didático apresentava exercícios e problemas baseados na experiência e no contexto socioeconômico e cultural do aluno. Desta forma, o autoaprendizado constituía-se, fundamentalmente, de uma pedagogia ativa. Aprendia-se fazendo.

A onda da correspondência até hoje é utilizada, apesar, de estar praticamente em desuso em tempos de internet. Porém, não podemos deixar de ressaltar como esta onda foi importante para a educação a distância, pois, foi por meio dela que se criaram os primeiros modelos de gestão de cursos com um grande número de alunos, o sistema de logística e também o desenvolvimento de uma modelo de produção de matéria didático impresso específico para a modalidade EAD.

\section{ONDA ESTUDO POR RÁDIO}

Em 1923, foi fundada a Rádio Sociedade do Rio de Janeiro. A principal função da emissora era possibilitar a educação popular por meio de um então moderno sistema de difusão em uso no Brasil e no mundo. Fazer uso desta tecnologia para educar a população brasileira, fazia parte de um "entusiasmo pela educação" característico da década de 20 , como afirma CARVALHO (1998):

[...] tinham como denominador comum a convicção de que a escolarização era 'o principal instrumento para o progresso do país', o 'entusiasmo pela edu- cação', característico da década de 20 (CARVALHO, 1998, p. 135)

O início do funcionamento da Rádio Sociedade do Rio de Janeiro ocorreu nas dependências de uma escola superior mantida pelo governo. Entretanto, esta junção de entidade privada e órgão público não durou muito tempo, sofrendo grandes pressões e exigências de difícil cumprimento. Em 1936, sem outra escolha, os instrutores precisaram doar à emissora para o ministério da Educação e Saúde. 
A educação por meio do rádio foi a segunda onda tecnológica da EAD, como afirma ALVES (2009, p. 09): "A educação via rádio foi, desta maneira, o segundo meio de transmissão a distância do saber, sendo apenas precedida pela correspondência”. 0 que alavancou esta onda foi a criação, em 1937, do serviço de Radiodifusão Educativo do Ministério da Educação, que permitiu a implantação de inúmeros programas, principalmente em rádios privadas.

Logo foi percebido o potencial do meio para superar obstáculos. Devido à abrangência e penetração social, o rádio oferecia a possibilidade de redução dos índices de analfabetismo, isso porque poderia atingir públicos que não eram contemplados pelo sistema escolar formal, oferecer escolarização suplementar e também a possibilidade de chegar a regiões de difícil acesso. Nesta perspectiva, vale trazer à tona as palavras de Roquette-Pinto apud (CASTRO, 2012), pai da radiodifusão brasileira, que definia o potencial do rádio para educação como:

O rádio é a escola dos que não tem escola. É o jornal de quem não sabe ler. É o mestre de quem não pode ir à escola. É o divertimento gratuito do pobre. É o animador de novas esperanças, o consolador dos enfermos e o guia do sãos - desde que realizado com espírito altruísta e elevado (CASTRO, 2012).

Movidos por este entusiasmo, diversas iniciativas foram criadas destacando-se a Escola Rádio-Postal, A voz da Proficiência e a Universidade no Ar. No nordeste, a experiência educativa por meio do rádio tem destaque o movimento de Educação de Base, criado pela Igreja Católica, por meio da diocese de Natal, Rio Grande do Norte.

Todas estas iniciativas foram importantes para o aprimoramento da educação por meio do rádio. Entretanto, foi nos anos 1960 e 1970 que ocorreu uma grande expansão nos números de sistemas radiofônicos de aprendizagem no país, desenvolvidos sob o comando das secretarias estaduais de ensino, fundações de caráter técnico educativo ou da Igreja Católica. Eram oferecidos, neste sistema, cursos regulares dedicados à alfabetização de adultos e à educação supletiva.

Nesse modelo, os alunos ingressavam por meio de inscrições que ocorriam nas secretarias de ensino, os alunos acompanhavam as aulas pelo rádio e era disponibilizado material didático impresso de apoio. Os cursos dispunham de três formas de acompanhamento: a recepção organizada, a recepção controlada e a recepção isolada ou individual. Santos (1970) as descreve como: recepção organizada, quando uma turma de alunos era reunida regularmente para ouvir as aulas e realizar atividades sob orientação de um monitor/tutor ou professor. Estes encontros poderiam ocorrer em escolas, igrejas ou em residências. Já na recepção controlada, o aluno ouvia a aula individualmente e desenvolvia as atividades propostas no material de apoio, depois deveria marcar um horário com o tutor para completar as atividades. Por fim, na última modalidade, o aluno desenvolvia suas atividades individualmente e depois realizava as avaliações junto com os alunos das outras duas formas de recepção.

Estas experiências do rádio no Brasil nos anos 60 e 70 estavam contempladas em um modelo que pouco explorava os recursos da linguagem radiofônica, faltando, sobretudo, o caráter impessoal do rádio. Isso gerou, segundo Bianco (2009), um elevado índice de evasão e, além deste problema, aponta ainda como outro motivo da grande evasão deste período a tentativa de reproduzir no rádio o modelo de educação presencial da escola.

O cenário desta onda só mudou nos anos 80 , quando foram introduzidas no Brasil as experiências do educador uruguaio Mario Kaplún. A contribuição de Kaplún é apresentada por Bianco (2009) como:

\footnotetext{
Mais do que transmitir conteúdos e modelar comportamento, a aprendizagem por rádio dede colaborar para que o sujeito aprenda a aprender, para alcançar este objetivo, Kaplún proponha que fosse superada a clássica divisão separa a dimensão educativa e a di-
} 
mensão do entretenimento na produção de programa. Isso implica em explorar de forma lúdica os diferentes recursos de linguagem e os formatos radiofônicos para criar um produto radiofônico educativo atraente para o publico alvo (BIANCO, 2009, p. 61).

A proposta pedagógica de Kaplún inspirou diversos projetos radiofônicos educativos que foram desenvolvidos tanto na esfera pública quanto na privada no Brasil da década de 90 . Foram projetos que propuseram o novo rompendo totalmente com os modelos anteriores. Nesta proposta, procurava-se dar ao estudante elementos para refletir sobre sua condição de cidadão com direito e deveres de sujeito ativo social e que possuía condições de influir na raridade.

A onda da educação por rádio ajudou a trazer para EAD um elemento importante na mediação a distância, pois por meio de uma linguagem lúdica e descontraída torna-se possível ao professor conseguir atrair a atenção e a curiosidade do aluno. Além deste aspecto, a oralidade, que já fazia parte do domínio das práticas docentes, ganha outros valores e é resignificada quando inserida nos recursos tecnologias dos alunos, como por exemplo, o uso dos podcasts nos Ambientes Virtuais de Aprendizado - AVA.

\section{ONDA ESTUDO POR COMPUTADOR SE LIGAÇÃO A REDE}

O CD-ROM foi uma tecnologia desenvolvida pela Philips e pela Sony em 1985 como meio para armazenamento de dados de computadores, usado o mesmo recurso físico utilizado nos discos compactos $C D$ (compact disc). No primeiro momento, o uso era somente para a leitura, os dados eram gravados pelo fabricante, depois foram lançados os discos compactos de leitura e gravação CD-RW (compact disc reading and writing) tornando possível a gravação e leitura de qualquer tipo de dados.

Em pouco tempo o CD-ROM tornou-se um dos meios digitais de armazenamento mais populares, substituindo definitivamente o disquete de 3,5 polegadas. Esta mudança ocorreu por um motivo muito simples: um CD-ROM convencional pode armazenar $682 \mathrm{Mb}$, que equivale aproximadamente a 473 disquetes com capacidade para $1,44 \mathrm{Mb}$, e com muito mais segurança e confiabilidade. Logo tal característica despertou diversas possibilidades. Uma delas é a possibilidade ir além da inserção do tradicional texto podendo inserir imagens, som e vídeo. A outra possibilidade é a alta capacidade de armazenamento e a utilização de outros meios que contribuíram na ten- tativa do CD-ROM substituir documentos impressos, como revistas livros ou até mesmo enciclopédias.

Todas estas características fizeram com que o CD-ROM aparecesse como recurso com grande potencial para a EAD. Comparado com o meio impresso, esta tecnologia se apresentou como um importante avanço no processo de armazenar e disseminação de informação. A possibilidade de desenvolver e distribuir informação em formato digital representava um grande avanço na EAD, pois, seria possível desenvolver conteúdos com animação e manipulação da informação, por mecanismo de indexação, busca e navegação hipertextual, contribuindo para que o aluno torne-se mais ativo.

Na busca de um aprendizado ativo, com uso do CD-ROM, as informações passaram a ser organizadas seguindo uma sequência pedagógica com duas formas: a tradicional, de forma linear ou hipertextual, num formato mais sofisticado, na qual o aluno poderia navegar pela informação. Porém, mesmo o aprendiz escolhendo o caminho por meio dos links, o fator principal é que os conteúdos e as informações foram 
planejados, ingeridas e organizadas previamente de forma limitada. Com o uso do CD-ROM a interação do aluno com o meio, ocorre nas escolhas disponíveis estabelecidas pelo software. 0 aprendiz obtém informação por meio de recursos multimídia, ou seja, imagem, som, vídeo, gráficos, textos e animações que, uma vez obtidas, podem refletir sobre ela e, com base nesta, podem selecionar outras opções.

As soluções de EAD que usam o CD-ROM podem ser classificadas em dois grupos: uso somente do CD-ROM e uso do CD-ROM combinado com material impresso. Na perspectiva de uso único deste recurso, este modelo foi muito utilizado no início da década de 90, quando os cursos de EAD buscavam ser mais inovadores e ofertar para seus alunos recursos diferentes aos do meio impresso. Tudo isso atrelado a um cenário tecnológico em que a internet não era tão disse- minada e a conexão ainda era feita por meio de linha discada. Na outra possibilidade de uso do CD-ROM combinado com recurso impresso, ocorreu como uma solução para combinar dois recursos na EAD, fazer uso de um recurso que já era bastante familiar do aluno e combiná-lo com algo moderno que iria complementar e ampliar os seus estudos, por meio de recursos multimedia.

A onda de estudo por computador sem ligação à rede, até hoje é utilizada, apesar, de estar praticamente em desuso devido ao avanço da internet no Brasil. Contudo, não podemos deixar de registrar a importância que esta onda teve para contribuir com o avanço do EAD, pois, foi por meio dela que pôde ser desenvolvida a produção de conteúdos hipertextuais, a aplicação de recursos multimedias que hoje são tão utilizados nos Ambientes Virtuais de Aprendizagem.

\section{ONDA ESTUDO POR E-LEARNING}

Nas últimas duas décadas, o crescimento da comunicação humana mediada pelo computador para fins educativos levou à criação de tecnologias que propiciassem a criação de ambientes educacionais on-line.

Com a introdução destes ambientes educativos on-line, a EAD ganha uma nova trajetória, pois agora emerge uma grande mudança na prática docente com novas reflexões sobre o papel do professor no processo ensino-aprendizagem. Na sala de aula virtual, o ambiente passa a ser diferente do presencial, onde não existem fisicamente paredes, cadeiras, mesas e quadro. Também ocorrem mudanças nas noções de tempo e espaço: o acesso pode ser feito de qualquer lugar a qualquer hora, desde que tenha acesso a grande rede. Passamos a ter um espaço educativo on-line, no qual a mediação ocorre por meio de interfaces digitais e professor e alunos são sujeitos ativos e colaborativos do processo de aprendizagem.

No Brasil, o uso de sistemas de gestão de aprendizagem, cujo nome original é LMS (Learning Management System), começa um pouco antes 2000, quando começa a ser utilizado pela primeira vez nas universidades brasileiras. Entretanto, o custo para ter um sistema como este era muito elevado e somente em 2003 os sistemas de gestão de aprendizagem começaram a ganhar popularidade no Brasil com o surgimento do Moodle. Tratava-se de uma iniciativa pioneira de disponibilização de um software de sistema de gestão de aprendizagem baseado em software livre, no qual as instituições poderiam disponibilizar seu próprio ambiente de aprendizagem na internet sem custos, porém ficariam obrigadas a disponibilizar para a comunidade de desenvolvedores do Moodle todas as modificações realizadas no sistema. Em pouco tempo começaram a 
surgir outros sistemas baseados em software livre, tornando popular o uso destes sistemas na EAD.

Fazer uso desta tecnologia representou uma revolução na Educação a Distância, pois, agora era possível ao professor realizar a mediação com seus alunos de forma síncrona, on-line, em tempo real, o que até então não era possível nas ondas anteriores. Além de propiciar a mediação professor/aluno, aluno/professor e aluno/aluno os Ambientes Virtuais de Aprendizado disponibilizam para o professor, novas interfaces de aprendizado como: chat, fórum, conteúdos multimedia, exercícios, avaliação, links, mensagens e muitos outros recursos. Fazer uso destas interfaces propiciou ao professor criar novas formas educar.

No AVA, o professor também dispõe de um conjunto de interfaces para poder fazer a gestão da aprendizagem dos seus alunos. Esta gestão ocorre na análise da informação gravada pelo sistema, assim o professor tem informações de quais conteúdos foram utilizados, a frequência que foi utilizada, frequência de acesso, o tempo gasto em cada atividade, o desempenho, o números de interações, em fim tudo o que acontece no ambiente gerara registro. Utilizar estas informações possibilita que o professor avalie o seu planejamento pedagógico e suas estratégias de mediação.

Com a utilização dos Ambientes Virtuais de Aprendizagem, a EAD conseguiu desenvolver a sua sala de aula, mas não uma sala física, e sim um espaço educativo que se utiliza de interfaces interativas, com possibilidades de comunicação multidirecional entre alunos e professores, o que propiciou à EAD a estar no mesmo patamar da educação presencial.

\section{CONSIDERACÕ̃ES FINAIS}

A partir das informações apresentadas nesse estudo, entende-se que a tecnologia no contexto da Educação a Distância é um elemento muito importante para o desenvolvimento da aprendizagem, visto que é por meio deste que se torna possível a união de dois agentes separados geograficamente e temporalmente, isto é, professor e aluno a favor de um único objetivo, que é a educação.

Trazer esta retórica tecnológica da EAD se fez necessário, pois foi fazendo uso e adaptando-se a estas tecnologias que a EAD construiu e construirá sua identidade, na qual os professores desenvolveram formas criativas para poder fazer a mediação como seu aluno, almejando sempre um único objetivo, que é estar perto, mesmo estando longe do seu aluno.

Mesmo com todo o avanço tecnológico da EAD, as estratégias de gestão e mediação das ondas anterio-

res formaram o alicerce. Assim, aprendemos com a onda das cartas os princípios da logística e como produzir o conteúdo impresso específicos para EAD. Com a onda do rádio, aprendemos a fazer uso da linguagem dos meios de comunicação, recurso tão importante na vídeo-aula, videoconferência e no podcasts. Já na onda do computador sem conexão com a rede, foram dados os primeiros passos na utilização de recursos multimídia e a hipertextualidade.

Assim, as ondas das tecnologias da EAD não terminam ou começam aqui, assim como o mar, onde não fica muito clara a separação entre as ondas. Elas sempre estarão em constante evolução e as tecnologias de hoje servirão como referencial para as tecnologias que virão. 


\section{REFERÊNCIAS}

ALVES, João Roberto Moreira. A história da EAD no Brasil in: LITTO. F. M; FORMIGA, M. M. (org). Educação a distância: o estado da arte. São Paulo: Pearson Education do Brasil, 2009, p. 9-13.

CARVALHO, Marta Maria Chagas de. A escola e a república e outros Ensaios. Bragança Paulista: EDUSF, 2003.

CASTRO, Rui. Roquette-Pinto: 0 Homem Multidão Disponível em: http://www.soarmec.com.br/roquette6.html Acesso em: 3 Jun. 2012.

IPEA. Rádio Educativo no Brasil: um estudo. Brasília, 1976, p. 134-135.

MOORE, Michael; KEARSLEY, Greg. Educação a distância: uma visão integrada. Tradução Roberto Galman. São Paulo: Thomson Learning, 2007.

OKADA, Alexandra Lilavati Pereira. Desafios para EAD: como fazer emergir a colaboração em ambientes virtuais de aprendizagem? In: SILVA, Marcos (Org.). Educação online: teorias, práticas, legislação, formação corporativa. São Paulo: Edições Loyola, 2003.

PALHARES, Roberto. Aprendizagem por Correspondência in: LITTO. F. M; FORMIGA, M. M. (org). Educação a distância: o estado da arte. São Paulo: Pearson Education do Brasil, 2009, p. 48-55.

RODRIGUES, Camila. Cursos por correspondência, hoje em desuso, recebiam mais de mil cartas por dia. Disponível em: http://educacao.uol.com.br/noti-

Recebido em: 29 de junho de 2012

Avaliado em: 9 de julho de 2012

Aceito em: 7 de agosto de 2012 cias/2012/05/16/cursos-por-correspondencia-hoje-em-desuso-recebiam-mais-de-mil-cartas-por-dia. htm Acesso em: 1 Jun. 2012.

SANTOS, B. C. A. Rádio Educativo: a participação da clientela no ensino supletivo. Tese (Mestrado em comunicação). Universidade de Brasilia. Brasília/DF, 1977.

SILVA, Marco Santos, EDMÉA. O Desenho didático interativo na educação online. Revista Iberoamericana de Educación. Número 49, 2009. Disponível em: http://www.rieoei.org/rie49a00b.pdf . Acesso em: 5 jun. 2012.

SILVA, Marcos. Criar e professorar em curso online: relato de experiência. In: SILVA, Marcos (Org.). Educação online. São Paulo: Edições Loyola, 2003.

TORI, Romero. Educação sem distância: as tecnologias interativas na redução de distância em ensino e aprendizagem. São Paulo, Editora Senac São Paulo, 2010.

VALENTE, José Armando. Aprendizagem por computador sem ligação à rede in: LITTO. F. M; FORMIGA, M. M. (org). Educação a distância: o estado da arte. São Paulo: Pearson Education do Brasil, 2009, p. 65-70.

1 Mestrando do Programa de Pós-Graduação em Educação da Universidade Tiradentes. Especialista em Gestão de Instituições de Ensino Superior (2008) pela Faculdade de Tecnologia e Ciências - FTC, graduação em Ciência da Computação pela Universidade Salvador UNIFACS (2006). Atualmente sou Coordenador de Tecnologias Educacionais do Núcleo de Educação a Distancia - NEAD da Sociedade de Educação Tiradentes. E-mail: lucas. vale@gmail.com

2 Professora Titular da Universidade Tiradentes (UNIT) no Programa de Pós-Graduação em Educação, na linha de pesquisa Educação e Comunicação. Doutora em Educação pela Universidade Federal da Bahia (2008). Mestre em Educação pela Universidade Federal de Santa Catarina (2004). Graduada em Pedagogia pela Universidade do Estado da Bahia (1995). Pesquisadora do Instituto de Tecnologia e Pesquisa (ITP-SE). E-mail: slucen@ yahoo.com.br - Brasil. 